\title{
Animal agriculture and the importance of agnostic governance of biotechnology
}

\author{
Alison L. Van Eenennaam* and Amy E. Young
}

\begin{abstract}
Human population growth and rising income levels in developing countries are increasing demand for animal protein. One of the key enablers of the associated increase in global animal protein production has been biotechnology, defined as, "any technological application that uses biological systems, living organisms or derivatives thereof to make or modify products or processes for specific use." Biotechnologies have directly benefitted the three core scientific disciplines of animal science-genetics, nutrition, and health. Significant potential remains to use biotechnologies to improve animal health. Globally, more than $20 \%$ of animal protein is lost as a result of disease. A number of diseases have been targeted by using recombinant DNA (rDNA) techniques in the breeding process to develop diseaseresistant food animals, although no such animals have yet been approved anywhere in the world. Part of the reason for this is that "modern" biotechnologies involving the use of rDNA are subject to a unique set of governance and regulatory requirements under the Cartagena Protocol on Biosafety and other national regulatory frameworks. The Protocol defines "modern biotechnology" as the application of in vitro nucleic acid techniques, including recombinant deoxyribonucleic acid (DNA) and direct injection of nucleic acid into cells or organelles, or fusion of cells beyond the taxonomic family, that overcome natural physiological reproductive or recombination barriers and that are not techniques used in traditional breeding and selection. In considering the impact of this modern biotechnology trigger for additional governance and regulatory oversight, a case study is presented of the various biotechnological approaches that might be employed to address the important tropical disease problem of African trypanosomiasis. Some approaches involve the use of natural gene drive systems ("selfish" gene elements that skew inheritance in their favor) and irradiation-induced sterile insect technique. Others involve techniques that trigger the modern biotechnology definition and include the use of an rDNA-derived paratransgenesis, a strategy that employs symbiotic microbes to control pathogens in vector populations, and the development of genetically engineered trypanosomiasis-resistant cattle. Despite the fact that all of these approaches are associated with potential harms and potential benefits, only those that involve the use of modern biotechnology such as rDNA techniques are subject to exceptional regulatory requirements. Triggering governance and regulatory oversight based on an arbitrarily-defined subset of techniques rather than on the outcomes or products resulting from the use of those techniques, does nothing to address the potential harms that might be associated with non-governed processes and disadvantages governed technologies with unique regulatory burdens. Even-handed evaluation that agnostically weighs the potential benefits and risks of products rather than the techniques used to produce those products is essential to ensure that the biotechnology best suited to addressing a problem can be employed, rather than a potentially less efficient approach that is chosen solely because it avoids the complicated regulatory frameworks that are uniquely triggered by the use of a modern biotechnology.
\end{abstract}

Keywords: Animal biotechnology, Genetic engineering, GMO, Sterile insect technique, Regulation, Governance

*Correspondence: alvaneenennaam@ucdavis.edu

Department of Animal Science, University of California, 2113 Meyer Hall,

One Shields Avenue, Davis, CA 95616, USA 


\section{Background}

On current trends, the United Nations Food and Agriculture Organization (FAO) projects that there will be a 73 percent increase in meat and egg consumption and a 58 percent increase in dairy consumption [1] over 2011 levels worldwide by the year 2050. Already, global meat production has more than doubled since 1970, increasing from 120 million tonnes to more than 270 million tonnes in 2010. Similarly, dairy production in the same period rose from 400 million tonnes to 690 million tonnes [2]. This change in production resulted both from dramatic improvements in the amount of product per animal due to genetic selection and improved nutrition [3], and increases in the sizes of animal populations. This latter point is perhaps most clearly illustrated by the fact that between 1980 and 2010 the world's population of chickens increased almost threefold, from 7.21 to 19.60 billion head [4]. For other livestock species, the current global populations are estimated to be 1.43 billion cattle, 1.87 billion sheep and goats, and 0.98 billion pigs [5]. One important driver for this dramatic increase in animal numbers and animal protein production, termed "the livestock revolution" [6], is growing demand for milk, meat and eggs. Two main forces are driving this demand for animal protein: human demographics and economic development.

Alongside the global livestock population, the world's human population has grown exponentially, from about 4 billion people in 1975 to more than 7 billion today. By 2050, this number is expected to rise to approximately 9.6 billion [7]. Paralleling the human population growth, the world economy has also been growing dramatically over recent decades, with a 20 -fold increase in global gross domestic product between 1970 and 2012 [4].

As incomes rise in developing economies, especially among traditionally undernourished populations, an initial increase occurs for dietary calorie intake of all food products equally, and then transitions to a decrease in per capita consumption of cereals and vegetables coupled with an increase in consumption of sugar, fats and animal products. This transition can lead to improved health because the overall nutritional value of animal protein is higher than that of staple foods such as cereals, roots and tubers. It has been shown that even small amounts of animal products can correct amino acid deficiencies in cereal-based human diets [8]. Consumption of milk and other animal-source foods by undernourished children improves anthropometric indices (weight-forheight, height-for-age and weight-for-age) and cognitive function and reduces the prevalence of biochemical and micronutrient deficiencies, reducing morbidity and mortality [9]. Animal source proteins are also more digestible and metabolized more efficiently than plant proteins, meaning they are more rapidly and readily available for use [10]. In one report, the consumption of meat was associated with a $36 \%$ decrease in the likelihood of stunting among toddlers (12-24 months) living in Guatemala, Democratic Republic of Congo, Zambia, and Pakistan [11]. This shift of food consumption patterns in developing countries towards livestock products is a major factor to be considered in the growth of world agriculture.

\section{The importance of animal disease}

It is interesting to note that developing economies actually produce more meat and milk than developed economies. However, this supply is still insufficient to meet demand due to the fact that much of the growth in the world's population and in incomes is also occurring in developing economies. Animal system productivity within developing regions is generally less than in developed countries owing to a combination of factors including inadequate animal nutrition (as a consequence of low feed quality, quantity and lack of nutritionally-balanced diets), lack of access to genetic selection techniques, and higher incidence of livestock disease [3]. Developing economies are faced with a number of human, zoonotic (can be transmitted between animals and humans) and livestock diseases, creating a major impediment to both economic development and food safety [4]. The World Organization for Animal Health (OIE) estimates that worldwide an average of more than $20 \%$ of animal protein is lost as a result of disease; therefore, significant potential exists to reduce this loss thereby decreasing the overall environmental impact per unit of animal protein production through improving the health of global livestock populations.

The widespread occurrence of animal disease in developing economies is one of the major factors negatively impacting livestock productivity in these countries. Generally, these diseases have the greatest impact on resource-poor livestock farmers and effective disease control is essential for poverty alleviation. Due to the devastating effects of disease on local livestock populations, many developing economies, particularly in subSaharan Africa, are net importers of livestock products. As a result, imports of livestock products from developed to developing economies are increasing. This is in part due to the fact that exports are confined to countries with officially confirmed and carefully monitored disease-free status and the absence of disease agents that are notifiable to the OIE. The net effect of these trends is that poor producers in some developing economies are unable to participate in supplying the domestic demand in their countries due to the prevalence of endemic animal diseases. Embracing solutions such as those afforded by various biotechnologies to prevent disease will be necessary 
to break this cycle of the economic effects of animal diseases and enable producers to participate in their local economies. This review will focus on the opportunities that biotechnologies offer to address some of the most pressing disease problems of animal agriculture and the use of these tools in meeting the global demands for animal protein.

\section{The role of biotechnology in animal production}

One of the key enablers of the increased global production of animal protein is biotechnology, which is defined by the Convention on Biological Diversity [12], as "any technological application that uses biological systems, living organisms or derivatives thereof to make or modify products or processes for specific use". The three core disciplines of animal science-genetics, nutrition, and health-have all benefited from a variety of biotechnological developments. Included under this broad heading are some relatively common and non-controversial biotechnologies such as artificial insemination (AI), use of genetic markers in breeding programs, feed additives, molecular diagnostics and vaccines. Others, such as cloning and the use of recombinant DNA (rDNA) technology to make transgenic or genetically engineered (GE) animals, recombinant vaccines and GE insects, have been associated with considerable controversy and often face both political and public opposition.

To date, the vast majority of biotechnologies have been produced and implemented in developed countries. However, various examples illustrate the potential of these approaches to improve health and productivity in livestock production systems and help reduce poverty and hunger in developing countries. The global elimination of Rinderpest (cattle plague) was achieved through a large-scale vaccination and surveillance program [13]. The sterile insect technique (SIT) has been used to suppress and locally eradicate or prevent the invasion of New World and Old World screwworms in North America (US), Netherlands, Central America and Libya [14]. The 2013 U.N. Food and Agriculture Organization (FAO) report, "Biotechnologies at Work for Smallholders: Case Studies from Developing Countries in Crops, Livestock and Fish," details 19 case studies in which agricultural biotechnologies were used to serve the needs of smallholders in developing countries. Among these was the application of SIT in Zanzibar to eradicate tsetse flies, the vector of trypanosomiasis. A common component of these successful programs has been global collaboration and investment by international organizations such as as the FAO, OIE, International Atomic Energy Agency (IAEA) and the World Health Organization (WHO), along with national political commitments.
These examples only provide a glimpse of the tremendous growth that has taken place in the fields of molecular genetics and genomics since the 1980s, and a range of DNA-based technologies are likely to play an increasingly important role in making future animal production more efficient, economical and sustainable. Some emerging rDNA-based technologies have the potential to address long-standing animal health issues that have proven intractable using traditional approaches. These technologies include GE animals that have been extensively reviewed elsewhere [15]. However, they are being deliberated in an often contentious global setting that includes the voices of many players, including the various bodies that are involved with international governance of animals and animal products, biosafety protocols, multinational animal activist and environmental corporations, and trade partners. Biotechnologies are increasingly being evaluated based not only on their technical effectiveness and feasibility, but also on their broader ethical and social implications, and this can lead to disagreements among interested parties depending upon their values and visions for a desirable future. It is important to employ the most suitable innovations, and in cases where that means rDNA technologies, it is becoming increasingly evident that evaluations need to be conducted in a manner that is agnostic to the technology used to achieve the result and focus on the unique risks and potential benefits that are associated with the end product or outcome.

Reducing livestock susceptibility to infectious diseases would seem to be a goal that aligns with most definitions of sustainability. Such a goal would improve animal welfare, decrease production losses and the use of therapeutic interventions such as antibiotics, and improve production efficiency. In fact, the goal of many traditional breeding programs in both plants and animals is to decrease host susceptibility to pests and disease. This target has been the ambitious goal of animal genetic engineers $[16,17]$ since the first GE livestock were generated almost 30 years ago [18]. In general, disease-resistant GE farm animals can be generated by either the introduction of resistance genes into the genome of the host (gainof-function strategy) or the targeting of endogenous or exogenous susceptibility genes (loss or exchange-offunction strategy) [19]. There are many extant examples where researchers have successfully modified the genomes of livestock to render them less susceptible to disease (Table 1). Despite these technical successes, there are currently no GE animals approved for food purposes anywhere in the world. Conversely, GE plants, which were first produced in 1983 [20], were approved for food purposes in the 1990s and have been rapidly adopted by farmers globally. Approximately 180 million hectares 
Table 1 Examples of successful modification of livestock genomes to render them less susceptible to disease

\begin{tabular}{lll}
\hline Disease & Species & References \\
\hline African swine fever & pigs & {$[47]$} \\
Avian influenza & chickens & {$[48]$} \\
Avian leukosis virus & chickens & {$[49]$} \\
Bacteria resistance & sheep/pigs/fish & {$[50-53]$} \\
Bovine spongiform encephalopathy & cattle, sheep & {$[54,55]$} \\
Bovine tuberculosis & cattle & {$[56]$} \\
Foot and mouth disease & various & {$[57]$} \\
Grass carp haemorrhage virus (GCHV) & fish & {$[58]$} \\
Influenza A \& classical swine fever & pigs & {$[59]$} \\
Mastitis/health of nursing offspring & various & {$[60-65]$} \\
Porcine reproductive and respiratory & pigs & {$[66]$} \\
syndrome virus (PRRSV) & & \\
Trypanosomiasis & various & {$[30]$} \\
Visna virus resistance & sheep & {$[67]$} \\
\hline
\end{tabular}

of GE crops (13\% of total arable land) were cultivated worldwide by 18 million farmers in 2014. Of these farmers, $94 \%$, or more than 17 million, were small acreage and resource-poor farmers in developing countries [21].

\section{Regulation of animal biotechnologies}

Part of the reason for the slow development of GE animals is that their potential deployment is associated with a daunting range of regulatory oversight and governance requirements from local and national governments, and international organizations. Globally, the Cartagena Protocol on Biosafety to the Convention on Biological Diversity (Protocol) is the preeminent instrument for the regulation of the products of GE technology at the international level. The stated objective of the Protocol relates to "the conservation and sustainable use of biological diversity", which may be adversely affected by the trade (or "transboundary movements") of "living modified organisms". "Biological diversity" (or biodiversity) refers to the number and variety of living organisms on the planet and is defined in terms of genes, species and ecosystems. The Protocol aims to ensure the safe handling, transport and use of living modified organisms (LMOs), both plants and animals, that "may have adverse effects on the conservation and sustainable use of biological diversity, taking also into account potential harms to human health", with specific focus on transboundary movements. The Protocol defines an LMO as any living organism that possesses a novel combination of genetic material obtained through the use of "modern biotechnology", which is defined as: (a) in vitro nucleic acid techniques, including recombinant deoxyribonucleic acid (DNA) and direct injection of nucleic acid into cells or organelles, or (b) fusion of cells beyond the taxonomic family that overcome natural physiological reproductive or recombination barriers and that are not techniques used in traditional breeding and selection. The Cartagena Protocol is therefore limited to the subset of biotechnology encompassed by the term "modern biotechnologies." Likewise, many national regulations are triggered by the use of rDNA technologies.

The United States of America (US) is not a party to the Cartagena Protocol. However, the trigger for the mandatory US Food and Drug Administration (FDA) regulation of GE animals is specified as those animals modified by rDNA techniques, including the entire lineage of animals that contain the modification. All GE animals are captured under these provisions, regardless of their intended use. Thus, although the regulatory evaluation is based on the product (the GE animal), the method used to produce the genetic change (i.e. rDNA versus other breeding methods) is the trigger for regulatory oversight. The fast-growing GE AquAdvantage salmon is the first GE animal to be evaluated by the FDA for food purposes. University researchers first produced the founder line for this strain in 1989 [22]. Despite the fact that the product has undergone nearly two decades of FDA regulatory scrutiny and the company has spent more than $\$ 77$ million on development and regulatory costs, no decision regarding the application to commercialize this fish had been made as of October 2015. Much of this delay has been associated with political interference in the science-based regulatory review [23]. In contrast, there is no regulatory oversight of the many lines of fast-growing livestock species, including fast-growing Atlantic salmon, that have been produced using conventional selection and breeding techniques.

\section{A case study: African trypanosomiasis}

In considering the impact of "modern biotechnology" or "rDNA" triggers for additional governance and regulatory oversight of biotechnological tools to address animal disease, a case study is presented of biotechnological approaches that might be employed to address the major tropical disease African trypanosomiasis. This disease, caused by blood parasites of the genus Trypanosoma that are transmitted by tsetse flies, affects human health, livestock production, agricultural production (lack of draught animals and manure), rural socio-economic development, national economies (import and export of animal products), and the environment (insecticide and trypanocide applications). The WHO estimates that there are currently 10,000-45,000 cases of human African trypanosomiasis (HAT), with 60 million people at risk in 36 African countries. Without treatment, infection is almost always fatal. 
Losses in livestock production due to African animal trypanosomiasis (AAT), or nagana, are estimated at US $\$ 1$ billion annually [24]. Direct losses in meat production and milk yield, plus the costs for trypanosomiasis control programs, are estimated at up to US $\$ 1.2$ billion each year. In many parts of sub-Saharan Africa (Fig. 1), the presence of tsetse flies is considered the major obstacle to the development of more efficient and sustainable livestock production systems and is one of the most important causes of hunger and poverty.

Current methods of controlling trypanosomiasis and the tsetse fly include: (1) SAT (sequential aerosol technique), an aerial application of extremely low volumes of nonresidual insecticides, (2) stationary bait techniques, i.e. use of insecticide-impregnated targets and traps that can be odor-baited, (3) the live bait technique, i.e. application of residual insecticides on livestock, (4) SIT (sterile insect technique), i.e. the release of sterile male insects, and (5) treatment of cattle with trypanocidal drugs [25]. The treatment of livestock with trypanocides and insecticides is associated with high costs, and resistance is developing to these pesticides and trypanocides. Due to the lack of effective vaccines (due to the high rate of antigenic variation by these blood parasites) and affordable drugs, vector control currently remains the most efficient strategy for sustainable disease management.

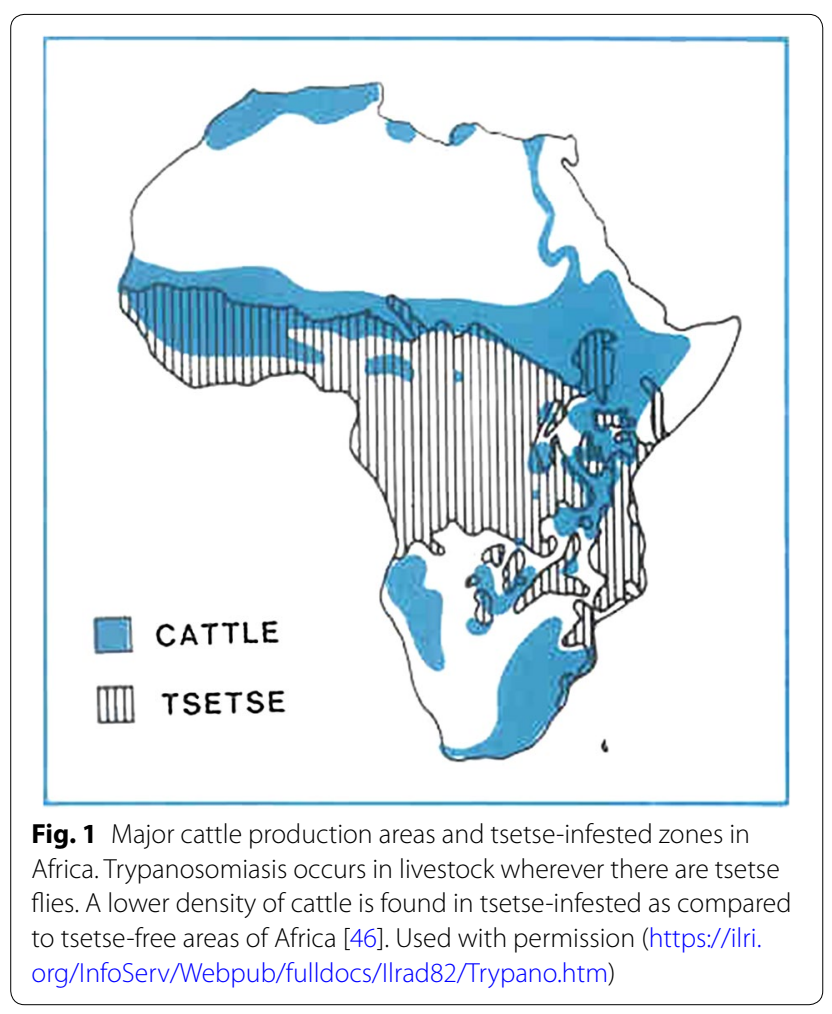

An example of this is the successful eradication of the tsetse population on Unguja Island (Zanzibar) using an area wide integrated pest management (AW-IPM) campaign. With a disease prevalence of $19 \%$, the rural farming communities were unable to maintain livestock as a basis for farming, food production, or income-generation prior to the program. The fly population was initially suppressed using insecticide-based control strategies. SIT was used as an important final component of the campaign to drive the population to extinction [26].

Following eradication, increases in livestock and crop productivity and animal availability for transport and draft purposes [26] resulted in substantial social and economic improvements. A $30 \%$ increase in yearly average income over 1999 levels was recorded in 2002. Demand increased for improved livestock breeds and the number of farmers raising improved cattle breeds increased from two percent in 1985 to 24 percent in 2002. During the same period, milk production nearly tripled and the proportion of farmers selling milk from indigenous cattle increased from 11 to 62 percent. Households with a monthly income of over US \$25 increased from 69 to 86 percent; and those with a monthly income of over US \$50 increased from 22 to 36 percent.

The project budget was approximately US \$3.5 million over 4 years. An additional US \$2 million included substantial insectary refurbishment, operational research, and many other activities including the need to establish large tsetse fly populations due to the reduced fitness of the males after irradiation, a facility to irradiate the males, and the weekly expenses involved with releasing sterile males. The successful eradication involved a substantial investment, but costs must be weighed against the many benefits obtained so far and those that are expected in the future, and against the cost of permanently investing in continuous suppression based on insecticides. This example is seen as a success story in the deployment of biotechnology to address an important disease problem.

In spite of these successes using a laboratory colony of the target species, efforts to establish mass rearing of tsetse colonies from the target field population revealed a susceptibility to salivary gland hypertrophy virus (SGHV). Despite initial success, the field colony experienced a steady decline over 2 years and collapsed [27]. The presence of SGHV in the wild tsetse has become a stumbling block for establishing and maintaining colonies for tsetse SIT control. A strategy to manage this tsetse virus will be required to continue this program.

As a result of the successes and limitations of SIT to date, complementary novel biotechnological approaches have recently been proposed and modeled to be sucessful. These involve manipulation of the symbiotic bacteria that have been found in tsetse flies, including the endosymbiont Sodalis glossinidius, and the reproductive symbiont 
Wolbachia pipientis. Wolbachia is an obligatory intracellular and maternally transmitted bacteria that gives the female tsetse flies in which it resides a reproductive advantage over female flies in which it does not, therefore becoming more common over time in the tsetse population. In insects, embryonic lethality occurs when an infected male is crossed with an uninfected female. This lethality rapidly biases inheritance in the population and increases the frequency of Wolbachia-infected insects by transmitting to the next generation with near $100 \%$ success, thereby creating a gene drive system for Wolbachia. This naturally occurring gene drive system can be used to increase the frequency of other maternally-inherited symbionts. Paratransgenesis, a term used to describe an insect carrying a GE microorganism typically modified to make the insect resistant to the disease-causing organism [28], can benefit from gene drive systems to spread the GE microorganism within an insect population. Sodalis glossinidius is ideally suited as a paratransgenic delivery system for anti-trypanosomal components to control parasite development in the fly. A strong gene drive system increases the power of paratransgenesis to replace non-transformed symbionts present in natural vector populations.

Another biotechnological approach that could be used to address trypanosomiasis would be the development of disease-resistant cattle. A consortium of scientists from the City University of New York, the International Livestock Research Institute (ILRI) in Nairobi, Kenya, the Roslin Institute, and Michigan University have been awarded a grant by The National Science Foundation of the USA and the Bill and Melinda Gates Foundation to develop GE cattle that are resistant to African Bovine Trypanosomiasis [29]. They plan to build upon work in transgenic mice where expression of a baboon trypanosome lytic factor resulted in sterile immunity (complete resistance) to trypanosomiasis [30].

In considering these various biotechnologies, radiationinduced SIT and the use of a Wolbachia-based invasive gene drive system would not be subject to rDNA regulations or the Cartagena Protocol on Biosafety, whereas paratransgenesis using GE bacteria, which would perhaps achieve the same goal of eliminating African tsetse and trypanosomiasis more effectively, would be subject to both. Gene drive was not an issue that was considered when the terms of the Cartagena Protocol were first negotiated. According to the Protocol, an advance informed agreement (AIA) procedure applies before the first environmental release of GE organisms in another country and grants the importing country the right to request the exporting country to perform a risk assessment at its own expense, part of which is to determine the likelihood of "unintentional transboundary movements".
In effect, the Wolbachia-based invasive gene drive system carrying the endosymbiont Sodalis glossinidiu would be beyond the scope of the Cartagena Protocol. However, if Wolbachia-carrying tsetse flies also carried a paratransgenic GE endosymbiont bacteria modified to control parasite development in the fly they would be covered by the Cartagena Protocol. Environmental release would likely be disallowed due to the high probability of the same "unintentional transboundary movements" associated with the Wolbachia-based invasive gene drive system, irrespective of the potential disease-control benefits that might be associated with the paratransgenic GE endosymbiont bacteria.

Similarly to paratransgenesis, GE cattle would be subject to the Protocol and, depending upon the country, would also likely fall under additional national regulations that may include both human health and environmental risk assessments, and an evaluation of the social and ethical implications of the resulting phenotype. Although such cattle could be of great benefit to people and livestock in the endemic areas through reduced incidence of trypanosomiasis, to livestock producers through increased profitability, and to the environment through reduced pesticide use, their use could conceivably result in an overall decline in biodiversity due to increased livestock production in areas that were previously unavailable due to trypanosomiasis. It is possible that an increase in cattle numbers resulting from increased survival could lead to detrimental environmental effects such as overgrazing which has been shown to be a contributor to land degradation and desertification. Although it might also be argued that there would be a decreased incidence of non-productive, chronically-ill cattle and that if farmers are confident of stock survival, they might be more willing to invest in improved health and grazing management programs. The eradication of the tsetse fly from Zanzibar was associated with an increase in cattle numbers, an outcome that was considered one of the benefits of the SIT-based eradication program, although the island location of this intervention may have limited the possible impacts of increased cattle numbers on biodiversity. This seemingly inconsistent appraisal of the impacts of biotechnologies developed using rDNA technologies as compared to those developed using non-rDNA approaches is difficult to reconcile from a scientific perspective. The potential harms associated with the products derived from rDNA technologies have proven no higher than those associated with the use of conventional technologies and may be less than those associated with existing production systems; and the benefits from these technologies are potentially high. It would seem that the potential impact of the outcomes of all proposed biotechnologies should be evaluated in the context of achieving 
a balance between the ethical mandate to control disease on a global scale, respect for the sovereignty of states, and an agnostic evaluation of the potential harms and potential benefits associated with the outcome that is expected to result from a proposed biotechnology in the context of existing production systems, irrespective of the technology that was used to develop it.

\section{Considerations and complications}

To some, addressing the problems of global hunger and poverty should be the key and perhaps principle drivers of technology adoption, but considerations such as the protection of biological diversity or animal integrity can complicate the issues. This leads to inherent conflicts when a technological approach leads to the destruction or detriment of an organism (e.g. a pest) that is causing disease or decreased productivity, or an increase in the number of an agricultural species like cattle. While some may see that outcome as helping food security, others may view it as decreasing biodiversity or subjecting a species to an undesirable, unnatural genetic manipulation. While both may agree that the technology is effectively decreasing the prevalence of the vector, disagreements may ensue as to whether this is a desirable outcome based on individual values. These differing worldviews sometimes play out in regulatory evaluations of modern biotechnologies, and although couched as scientificallybased risk evaluations, factors regarding the desirability of the innovation, including ethical and social considerations and not science, often drive regulatory decisions. Regulation is increasingly being used to prevent the deployment of potentially beneficial biotechnologies based on contrasting values and visions for the future.

A 2012 decision in the Philippines regarding the introduction of a GM insect-resistant talong (eggplant) [through the insertion of a gene from Bacillus thuringiensis $(\mathrm{Bt})]$ provides an example of this conflict. In considering this technological development, the Court of Appeals in the Philippines ruled against allowing experiments on Bt talong using an argument in support of biodiversity [31]; in this case, the biodiversity was represented by a species of borers that consume talong. The ruling stated "It is a deliberate genetic reconstruction of the eggplant to alter its natural order which is meant to eliminate one feeder (the borer) in order to give undue advantage to another feeder (the humans). The genetic transformation is one designed to make Bt talong toxic to its pests (the targeted organisms). In effect, Bt talong kills its targeted organisms. Consequently, the testing or introduction of Bt talong into the Philippines, by its nature and intent, is a grave and present danger to (and an assault on) the Filipinos' constitutional right to a balanced ecology because, in any book and by any yardstick, it is an ecologically imbalancing event or phenomenon. It is a willful and deliberate tampering of a naturally ordained feed-feeder relationship in our environment. It destroys the balance of our biodiversity. Because it violates the conjunct right of our people to a balanced ecology, the whole constitutional right of our people (as legally and logically construed) is violated". The decision is now on appeal in the Supreme Court of the Philippines.

This decision valued avoidance of a potential threat to biodiversity by targeting an agricultural pest over potential benefits associated with the pest-resistant product or the fact that pests threaten agricultural production systems and food security. All agricultural systems involve using selected crop and animal varieties and altering the species composition of a given ecosystem, presumably to the advantage of food production and human "feeders" and to the disadvantage of pests, weeds, and less productive food species. Frequently, agricultural technologies associated with pest control are controversial. Herbicides, insecticides, fungicides and antibiotics are all employed to control pests that threaten food production, namely weeds, insects, fungi and pathogens. Oftentimes, groups opposed to the use of these technologies in agricultural production systems examine only the potential harms or downsides, such as the potential development of resistance, and do not consider the benefits of their use or the tradeoffs that are associated with precluding their use. It has been estimated that without pesticides $70 \%$ of the world food crop would be lost and, even with pesticide use, $42 \%$ is destroyed by insects and fungal damage [32]. Dispensing with pesticides would require at least $90 \%$ more cropland to maintain present yields [33]. Likewise, the development of disease-resistant varieties of plants and animals is associated with potential harms, benefits and tradeoffs. Ironically, the tradeoffs associated with limiting or precluding the use of rDNA in the process of breeding disease-resistant animals are likely to include diminished animal welfare, decreased animal protein production, per animal thereby necessitating an increased number of animals to produce a given quantity of protein, and an increased use of antibiotics and other pesticides (e.g. insecticides) to help control animal diseases around the world.

\section{Perspective}

The rDNA process-based governance of animal biotechnology is being increasingly questioned [34], and it is becoming difficult to justify given our increased understanding of genomes and the unfortunate fact that the current governance situation is resulting in the avoidance or abandonment of potentially useful applications that could be enabled by these technologies. The lack of scientific certainty about any potential adverse effects 
on biological diversity can be used to delay, or at worst permanently forestall, the adoption of potentially beneficial LMOs produced using modern biotechnologies. The precautionary principle requires no assessment or judgement of the potential benefits of a given modification, nor consideration of the opportunity costs associated with continuing to use existing animal genetic resources. This situation was perhaps most tersely summarized by Dr. Wells of the University of Missouri in Columbia in 2013, "The basic premise for regulation appears to be that any genotype produced by breeding is safe, and that any genotype produced intentionally via rDNA technologies cannot be allowed to go to market" [35].

Further complicating these regulatory issues are newlyavailable precision gene editing techniques that precisely mimic naturally-occurring evolutionary mutations, a process that can leave no DNA-based signature of modification in the genome to regulate. Recent review papers [36-38] summarize the use of site-specific designer nuclease genome editing techniques to improve livestock for agriculture. These methods are being used to explore a variety of approaches to address issues affecting animal agriculture. These include genetic research on generating offspring of a single sex for animal industries where one sex is favored (e.g. egg and dairy) [39, 40], development of genetic approaches for avoiding painful procedures such as dehorning and castration $[40,41]$ to improve animal welfare, and gene knockout approaches to preclude the production of endogenous proteins such as food allergens and prion proteins [42-44] to improve food safety. Many of these applications are directed towards improved animal welfare and again would seem to align with many definitions of sustainability. It is currently unclear whether these techniques, which do involve the "application of in vitro nucleic acid techniques", but frequently introduce genetic variation that is indistinguishable from naturally-occurring alleles induced by spontaneous mutation, will be subject to the modern biotechnology regulatory governance, especially given there is often no rDNA sequence(s) present in the product.

Similarly, disease vectors are also being targeted with these techniques. Mosquitoes are known to transmit a number of pathogens that cause diseases such as yellow fever, dengue and chikungunya. Together, these infections are responsible for more than 50,000 human deaths each year. A recent report details the use of genome engineering via the CRISPR-Cas9 system to generate stable germline mutations in the mosquito Aedes aegypti. The authors suggested that the techniques outlined in their paper could be useful not only for addressing the diseasetransmitting abilities of $A$. aegypti through a variety of mutant alleles, but also for modifying other non-model organisms [45].
Triggering governance and regulatory oversight based on the use of modern biotechnologies in the development process, rather than on the outcomes or products resulting from the use of those technologies, is ineffective for addressing those risks that might be associated with non-governed processes and disadvantages governed technologies with unique regulatory burdens. If the risks and potential benefits resulting from a particular novel phenotype (e.g. disease-resistance) are the same, there would seem to be no rationale for regulating and increasing the development and implementation costs of only those produced using specific techniques (e.g. rDNA) in the breeding program. Perhaps more importantly, in some cases the risks and ecological impacts associated with unregulated processes or existing production systems may in fact be greater than those associated with using systems that employ modern biotechnological approaches.

Even-handed, technology-agnostic evaluation of animal biotechnologies is essential to ensure that one strategy is not chosen over another solely because it avoids onerous regulations. Regulation and governance to ensure the safety and responsible use of new technologies is necessary. However, such efforts should be proportional to the unique risks posed by the product being evaluated, and should not be triggered on the technique or biotechnology that was used to produce those products. Currently, identical products produced using different biotechnologies are subject to very different levels of scrutiny. It is perhaps this lack of logical consistency that most frustrates scientists working to develop new agricultural technologies. It is time to carefully evaluate and weigh both any unique risks and potential benefits posed by novel traits developed in animal breeding programs, irrespective of the breeding method that was used to introduce those traits. Overly burdensome regulation of modern biotechnologies is forestalling the development of solutions to real-world agricultural problems.

\section{Conclusion}

The stated objective of the Cartegena Protocol is "the conservation and sustainable use of biological diversity". However, as it is written it only covers transboundary movements of "living modified organisms" produced using specific modern biotechnologies, and considers only the potential risk associated with such developments. It ignores the fact that novel organisms created by traditional breeding and selection techniques may pose equivalent or greater risk, and also the opportunity costs associated with the delayed adoption of beneficial products that have been shown to be safe. And because the trigger is defined as a specific subset of biotechnologies, the definition may become outdated as technologies to 
make subtle changes to the genome evolve. Good public policy requires that regulation be clearly targeted to address an identified problem. Modern biotechnologies have not proven to be uniquely risky, and it is the attributes of the resulting organism that present both potential risks and benefits, regardless of the technology that was used to develop that organism.

The concern with the current governance of animal biotechnologies is that it actually results in an illogical incentive to pursue those technical approaches that are exempt from regulatory oversight, irrespective of the relative technical feasibility, likelihood of success, speed, potential harms, and potential benefits. A less effective, non-regulated approach may be preferred to a more precise, effective, and efficient regulated approach. In a world facing burgeoning demands for animal-source protein, creating arbitrary regulatory hurdles for potentially beneficial uses of modern animal biotechnologies based solely on their use of in vitro nucleic acid techniques cannot be justified scientifically, and is hindering the development of more productive animal agricultural systems globally.

\section{Abbreviations}

AW-IPM: area wide integrated pest management; Cl: cytoplasmic incompatibility; FAO: United Nations Food and Agriculture Organization; FDA: US Food and Drug Administration; GE: genetically engineered; HAT: human African trypanosomiasis; IAEA: International Atomic Energy Agency; LMOs: living modified organisms; OlE: World Organization for Animal Health; Protocol: Cartagena protocol on biosafety to the convention on biological diversity; rDNA: recombinant DNA; SGHV: salivary gland hypertrophy virus; SIT: sterile insect technique; US: United States of America; WHO: World Health Organization.
\end{abstract}

\section{Authors' contributions}

AVE initiated this review and wrote and developed the content of this manuscript. AEY contributed to the literature review and assisted with writing and editing. Both authors read and approved the final manuscript.

\section{Authors' information}

AVE is an Animal Genomics and Biotechnology Extension Specialist in the Department of Animal Science at the University of California, Davis. AEY is a Staff Research Associate and manages the Van Eenennaam Laboratory at the University of California, Davis.

\section{Acknowledgements}

The authors would like to acknowledge support from the W. K. Kellogg endowment and the California Agricultural Experiment Station of the University of California, Davis, for the preparation of this paper.

\section{Competing interests}

The authors declare that they have no competing interests.

Received: 7 June 2015 Accepted: 29 October 2015

Published online: 23 November 2015

\section{References}

1. Food and Agriculture Organization of the United Nations (FAO). World Livestock 2011_Livestock in food security. Rome: FAO; 2011.
2. Guyomard H, Manceron S, Peyraud J-L. Trade in feed grains, animals, and animal products: current trends, future prospects, and main issues. Anim Front. 2013;3(1):14-8.

3. Capper $\mathrm{J}$, Bauman DE. The role of productivity in improving the environmental sustainability of ruminant production systems. Annu Rev Anim Biosci. 2013;1:469-89.

4. Food and Agriculture Organization of the United Nations (FAO). World Livestock 2013_changing disease landscapes. Rome. 2013. http://www.fao.org/docrep/019/i3440e/i3440e.pdf. Accessed 26 May 2015.

5. Robinson TP, Wint GR, Conchedda G, Van Boeckel TP, Ercoli V, Pala-

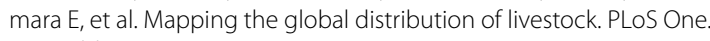
2014;9(5):e96084.

6. Delgado CL, Rosegrant MW, Steinfeld H, Ehui SK, Courbois C. Livestock to 2020: the next food revolution. Intl Food Policy Res Inst, Food, Agriculture, and the Environment Discussion Paper 28. 1999; 28:1-74. http://www. animalbiotechnology.org/livestock\%20revolution.pdf. Accessed 26 May 2015

7. United Nations, Department of Economic and Social Affairs, Population Division. World Population Prospects: The 2012 revision, key findings and advance tables. Working Paper No. ESA/WP.227. 2013. http://esa.un.org/ wpp/documentation/pdf/wpp2012_\%20key\%20findings.pdf. Accessed 13 Oct 2015.

8. Miller BDD, Welch RM. Food system strategies for preventing micronutrient malnutrition. Food Policy. 2013;42:115-28.

9. Dror DK, Allen LH. The importance of milk and other animal-source foods for children in low-income countries. Food Nutr Bull. 2011;32(3):227-43.

10. McNeill S, Van Elswyk ME. Red meat in global nutrition. Meat Sci. 2012;92(3):166-73.

11. Krebs NF, Mazariegos M, Tshefu A, Bose C, Sami N, Chomba E, et al. Meat consumption is associated with less stunting among toddlers in four diverse low-income settings. Food Nutr Bull. 2011;32(3):185-91.

12. Convention on Biological Diversity Handbook (3rd Edition). 1992. https:// www.cbd.int/doc/handbook/cbd-hb-01-en.pdf. Accessed 29 Sep 2015.

13. Roeder PL. Rinderpest: the end of cattle plague. Prev Vet Med. 2011;102(2):98-106.

14. Vargas-Terán M, Hofmann HC, Tweddle NE. Impact of screwworm eradication programmes using the sterile insect technique. In: Dyck VA, Hendrichs J, Robinson AS, editors. Sterile Insect Technique. Springer: Netherlands; 2005. p. 629-50.

15. Forabosco F, Lohmus M, Rydhmer L, Sundstrom LF. Genetically modified farm animals and fish in agriculture: a review. Livest Sci. 2013;153(1-3):1-9.

16. Müller M, Brem G. Transgenic approaches to the increase of disease resistance in farm animals. Rev Sci Tech. 1998;17(1):365-78.

17. Whitelaw CB, Sang HM. Disease-resistant genetically modified animals. Rev Sci Tech. 2005;24(1):275-83.

18. Hammer RE, Pursel VG, Rexroad CE Jr, Wall RJ, Bolt DJ, Ebert KM, et al. Production of transgenic rabbits, sheep and pigs by microinjection. Nature. 1985;315(6021):680-3

19. Lassnig C, Müller M. Disease-resistant transgenic animals. In: Christou P, Savin R, Costa-Pierce B, Misztal I, Whitelaw CB, editors. Sustainable food production. New York: Springer; 2013. p. 747-60.

20. Bevan MW, Flavell RB, Chilton M-D. A chimaeric antibiotic resistance gene as a selectable marker for plant cell transformation. Nature. 1983;304(5922):184-7

21. James C. Global status of commercialized biotech/GM Crops: 2014. ISAAA Brief No 49. ISAAA: Ithaca, NY.

22. Du SJ, Gong Z, Fletcher GL, Shears MA, King MJ, Idler DR, et al. Growth enhancement in transgenic atlantic salmon by the use of an "all fish" chimeric growth hormone gene construct. Nat Biotechnol. 1992;10(2):176-81.

23. Van Eenennaam AL, Muir WM. Transgenic salmon: a final leap to the grocery shelf? Nat Biotechnol. 2011;29(8):706-10.

24. Kristjanson PM, Swallow BM, Rowlands GJ, Kruska RL, de Leeuw PN. Measuring the costs of African animal trypanosomosis, the potential benefits of control and returns to research. Agr Syst. 1999;59(1):79-98.

25. Vreysen MJB, Seck MT, Sall B, Bouyer J. Tsetse flies: their biology and control using area-wide integrated pest management approaches. $J$ Invertebr Pathol. 2013;112(Suppl 1):S15-25. 
26. Vreysen MJB, Saleh K, Mramba F, Parker A, Feldmann U, Dyck VA, et al. Sterile insects to enhance agricultural development: the case of sustainable tsetse eradication on Unguja Island, Zanzibar, using an area-wide integrated pest management approach. PLoS Neglect Trop D. 2014;8(5):e2857.

27. Kariithi HM, Ahmadi M, Parker AG, Franz G, Ros VI, Haq I, et al. Prevalence and genetic variation of salivary gland hypertrophy virus in wild populations of the tsetse fly Glossina pallidipes from southern and eastern Africa. J Invertebr Pathol. 2013;112(Suppl):S123-32.

28. De Vooght L, Caljon G, De Ridder K, Van Den Abbeele J. Delivery of a functional anti-trypanosome nanobody in different tsetse fly tissues via a bacterial symbiont, Sodalis glossinidius. Microb Cell Fact. 2014;13:156.

29. Willyard C. Putting sleeping sickness to bed. Nat Med. 2011;17(1):14-7

30. Thomson R, Molina-Portela P, Mott H, Carrington M, Raper J. Hydrodynamic gene delivery of baboon trypanosome lytic factor eliminates both animal and human-infective African trypanosomes. Proc NatlAcad Sci USA. 2009;106(46):19509-14.

31. Republic of the Philippines, Court of Appeals, Greenpeace Southeast Asia vs. Environmental Management Bureau of the Department of Environment and Natural Resources, CA-G.R. SP NO. 00013. http://www.ensser.org/fileadmin/ files/NoticeOfDecision-CA-G.R.SP-No.00013.pdf. Accessed 30 Sep 2015.

32. Pimentel D, Wilson C, McCullum C, Huang R, Dwen P, Flack J, et al. Economic and environmental benefits of biodiversity. Bioscience. 1997:47(11):747-57.

33. Trewavas AJ. The population/biodiversity paradox. Agricultural efficiency to save wilderness. Plant Physiol. 2001;125(1):174-9.

34. Bruce A, Castle D, Gibbs C, Tait J, Whitelaw CB. Novel GM animal technologies and their governance. Transgenic Res. 2013;22(4):681-95.

35. Wells KD. Natural genotypes via genetic engineering. Proc Natl Acad Sci USA. 2013;110(41):16295-6.

36. Bosch P, Forcato DO, Alustiza FE, Alessio AP, Fili AE, Olmos Nicotra MF, et al. Exogenous enzymes upgrade transgenesis and genetic engineering of farm animals. Cell Mol Life Sci. 2015;72(10):1907-29.

37. Laible G, Wei J, Wagner S. Improving livestock for agriculture-technological progress from random transgenesis to precision genome editing heralds a new era. Biotechnol J. 2015;10(1):109-20.

38. Rajendran SR, Yau YY, Pandey D, Kumar A. CRISPR-Cas9 based genome engineering: opportunities in agri-food-nutrition and healthcare. Omics. 2015;19(5):261-75.

39. Fan Z, Lee S, Park H, Lucibello K, Meng Q, Polejaeva I, et al. Genetic inactivation of the SRY gene in Argali wild and Romney domestic sheep with CRISPR/Cas systems for producing sex-reversed female animals. Reprod Fert Develop. 2013;26(1):167.

40. Tan W, Carlson DF, Lancto CA, Garbe JR, Webster DA, Hackett PB, et al. Efficient nonmeiotic allele introgression in livestock using custom endonucleases. Proc Natl Acad Sci USA. 2013;110(41):16526-31.

41. Tan WS, Carlson DF, Walton MW, Fahrenkrug SC, Hackett PB. Precision editing of large animal genomes. Adv Genet. 2012;80:37-97.

42. Yao J, Huang J, Hai T, Wang X, Qin G, Zhang H et al. Efficient bi-allelic gene knockout and site-specific knock-in mediated by TALENs in pigs. Sci Rep. 2014;4:6926.

43. Ni W, Qiao J, Hu S, Zhao X, Regouski M, Yang M, et al. Efficient gene knockout in goats using CRISPR/Cas9 system. PLoS One. 2014;9(9):e106718.

44. Proudfoot C, Carlson DF, Huddart R, Long CR, Pryor JH, King TJ, et al. Genome edited sheep and cattle. Transgenic Res. 2015;24(1):147-53.

45. Kistler Kathryn E, Vosshall Leslie B, Matthews Benjamin J. Genome engineering with CRISPR-Cas9 in the mosquito aedes aegypti. Cell Rep. 2015;11(1):51-60

46. International Livestock Centre for Africa. Livestock productivity and trypanotolerance. Nairobi, Kenya. 1981. pp. 59-63.

47. Lillico SG, Proudfoot C, Carlson DF, Stverakova D, Neil C, Blain C et al. Live pigs produced from genome edited zygotes. Sci Rep. 2013;3:2847.
48. Lyall J, Irvine RM, Sherman A, McKinley TJ, Núñez A, Purdie A, et al. Suppression of avian influenza transmission in genetically modified chickens. Science. 2011;331(6014):223-6.

49. Salter DW, Crittenden LB. Artificial insertion of a dominant gene for resistance to avian leukosis virus into the germ line of the chicken. Theoret Appl Genetics. 1989;77(4):457-61.

50. Lo D, Pursel V, Linton PJ, Sandgren E, Behringer R, Rexroad C, et al. Expression of mouse IgA by transgenic mice, pigs and sheep. Eur J Immunol. 1991;21(4):1001-6.

51. Dunham RA, Warr GW, Nichols A, Duncan PL, Argue B, Middleton D, et al. Enhanced bacterial disease resistance of transgenic channe catfish Ictalurus punctatus possessing cecropin genes. Mar Biotechnol. 2002:4(3):338-44

52. Weifeng M, Yaping W, Wenbo W, Bo W, Jianxin F, Zuoyan Z. Enhanced resistance to Aeromonas hydrophila infection and enhanced phagocytic activities in human lactoferrin-transgenic grass carp (Ctenopharyngodon idellus). Aquaculture. 2004;242(1-4):93-103.

53. Fletcher GL, Hobbs RS, Evans RP, Shears MA, Hahn AL, Hew CL. Lysozyme transgenic Atlantic salmon (Salmo salar L.). Aquac Res. 2011;42(3):427-40.

54. Richt JA, Kasinathan P, Hamir AN, Castilla J, Sathiyaseelan T, Vargas F, et al. Production of cattle lacking prion protein. Nat Biotech. 2007;25(1):132-8

55. Denning C, Burl S, Ainslie A, Bracken J, Dinnyes A, Fletcher J, et al. Deletion of the alpha(1,3)galactosyl transferase (GGTA1) gene and the prion protein (PrP) gene in sheep. Nature Biotech. 2001;19(6):559-62.

56. Wu H, Wang Y, Zhang Y, Yang M, LV J, Liu J, et al. TALE nickase-mediated SP110 knockin endows cattle with increased resistance to tuberculosis. Proc Natl Acad Sci USA. 2015;112(13):E1530-9.

57. Jiao Y, Gong X, Du J, Liu M, Guo X, Chen L, et al. Transgenically mediated shRNAs targeting conserved regions of foot-and-mouth disease virus provide heritable resistance in porcine cell lines and suckling mice. Vet Res. 2013;44(1):47.

58. Zhong J, Wang Y, Zhu Z. Introduction of the human lactoferrin gene into grass carp (Ctenopharyngodon idellus) to increase resistance against $\mathrm{GCH}$ virus. Aquaculture. 2002;214(1-4):93-101.

59. Yan $Q$, Yang $H$, Yang D, Zhao B, Ouyang Z, Liu Z, et al. Production of transgenic pigs over-expressing the antiviral gene Mx1. Cell Regeneration. 2014;3(1):11.

60. Maga EA, Cullor JS, Smith W, Anderson GB, Murray JD. Human lysozyme expressed in the mammary gland of transgenic dairy goats can inhibit the growth of bacteria that cause mastitis and the cold-spoilage of milk. Foodborne Pathog Dis. 2006;3(4):384-92.

61. Wall RJ, Powell AM, Paape MJ, Kerr DE, Bannerman DD, Pursel VG, et al. Genetically enhanced cows resist intramammary Staphylococcus aureus infection. Nat Biotech. 2005;23(4):445-51

62. Zhang J, Li L, Cai Y, Xu X, Chen J, Wu Y, et al. Expression of active recombinant human lactoferrin in the milk of transgenic goats. Protein Express Purif. 2008;57(2):127-35.

63. Bleck GT, White BR, Miller DJ, Wheeler MB. Production of bovine alphalactalbumin in the milk of transgenic pigs. J Anim Sci. 1998;76(12):3072-8.

64. Wheeler MB, Bleck GT, Donovan SM. Transgenic alteration of sow milk to improve piglet growth and health. Reproduction Suppl. 2001;58:313-24

65. Yang B, Wang J, Tang B, Liu Y, Guo C, Yang P, et al. Characterization of bioactive recombinant human lysozyme expressed in milk of cloned transgenic cattle. PLoS One. 2011;6(3):e17593.

66. Li L, Li Q, Bao Y, Li J, Chen Z, Yu X, et al. RNAi-based inhibition of porcine reproductive and respiratory syndrome virus replication in transgenic pigs. J Biotechnol. 2014;171:17-24.

67. Clements JE, Wall RJ, Narayan O, Hauer D, Schoborg R, Sheffer D, et al. Development of transgenic sheep that express the visna virus envelope gene. Virology. 1994;200(2):370-80. 